\title{
Gallic Acid Dimer As a Double $\pi$-Hole Donor: Evidence from X-ray, Theoretical Calculations, and Generalization from the Cambridge Structural Database
}

Rafel Prohens, ${ }^{* \dagger, \dagger}$ Dafne de Sande, ${ }^{\ddagger}$ Mercè Font-Bardia, ${ }^{\S}$ Antonio Franconetti, ${ }^{\|}$José F. González, ${ }^{\perp}$ and Antonio Frontera ${ }^{*}$;

$\dagger$ Unitat de Polimorfisme i Calorimetria, Centres Científics i Tecnològics, Universitat de Barcelona, Baldiri Reixac 10, 08028 Barcelona, Spain

$\$$ Center for Intelligent Research in Crystal Engineering S.L., Palma de Mallorca, Spain

$\S$ Unitat de Difracció de Raigs X, Centres Científics i Tecnològics, Universitat de Barcelona, Barcelona, Spain

|| Departament de Química, Universitat de les Illes Balears, Crta de Valldemossa km 7.5, 07122 Palma de Mallorca, Baleares, Spain

$\perp$ Serveis CientíficoTecnics, Universitat de les Illes Balears, Crta de Valldemossa km 7.5, 07122 Palma de Mallorca, Baleares, Spain 
49 In this work, we demonstrate that the centrosymmetric eight-membered supramolecular ring R2 2 (8)

50 that is formed upon dimerization of benzoic acids has a marked tendency to establish $\pi$-hole interactions

51 with electron-rich atoms. We have used the Cambridge Structural Database to demonstrate the

52 preference of carboxylic acid dimers to form donor-acceptor interactions involving $\pi$-holes located at

53 the $\mathrm{C}$ atoms above and below the molecular plane. Moreover, we have carried out DFT calculations

54 (PBE0-D3/def2-TZVP) to investigate the geometric and energetic features of these interactions and how

55 they are affected by the substituents of the aromatic ring. Finally, as an example we report the synthesis

56 and X-ray characterization of a solvate of gallic acid with dioxane, where two molecules of dioxane are

57 located above and below the eight-membered supramolecular ring, forming two symmetrically

58 equivalent $\mathrm{O} \cdots \mathrm{C} \pi$-hole interactions.

59

60

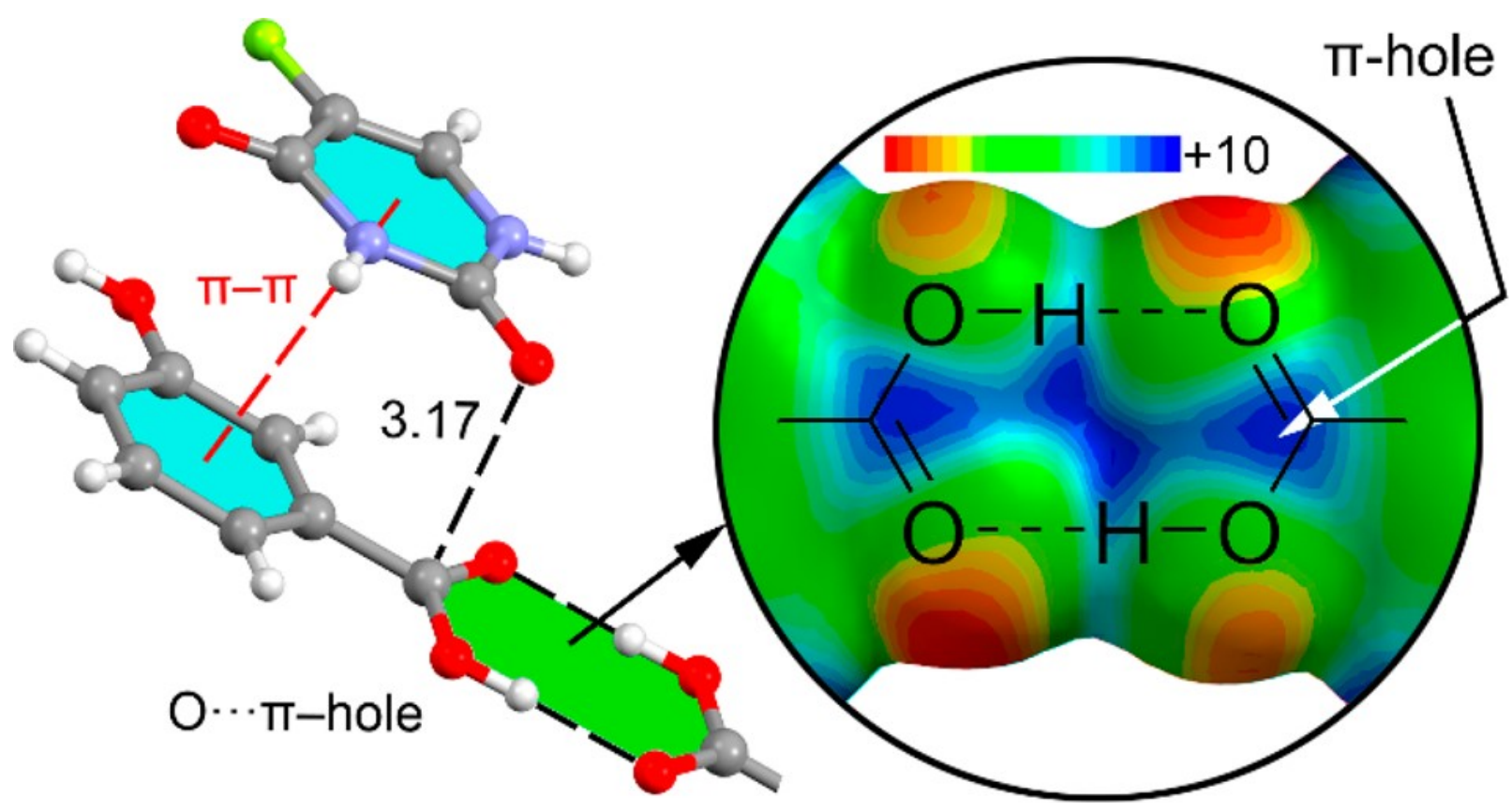


67 The ultimate goal of crystal engineering is actually property engineering, which is, so far, unreachable.

68 Desiraju's definition of crystal engineering was basically composed by two parts: (i) "the understanding

69 of intermolecular interactions in the context of crystal packing" and (ii) "the utilization of such understanding in the design of new solids with desired physical and chemical properties."1 The full accomplishment of the first part is needed to start progressing on the second part.2 In fact, the progress on the second part has been achieved either from a serendipitous finding 3 or by optimizing known structures. 4 Therefore, a deep knowledge of the factors that govern crystal packing is necessary, which involves a deep understanding of noncovalent interactions.

For decades, most of the scientific attention has been focused on the hydrogen bond.5-8 More recently, several structurally and energetically related noncovalent interactions have gained increasing attention in several areas.9-16 Many of these bonds derive from the $\sigma$-hole concept wherein a main group element,17,18 even an electronegative atom, can attract a nucleophile through an anisotropic electronic distribution, which offers a positive MEP (molecular electrostatic potential) in a region that is located at the extension of a covalent bond.19,20 The $\sigma$-hole region is usually small, thus leading to very directional interactions. The acidic $\sigma$-hole region is thus adequate for attracting negative sites (lone pairs, anions, or $\pi$ - electron systems).21-30 In addition to these $\sigma$-holes located opposite to a covalent bond, some molecules also exhibit $\pi$-holes, which lie usually above and below the plane of the system,31-36 leading to $\pi$-hole bonded complexes upon interaction with nucleophiles. 37 In this respect, $\pi$-hole interactions in X-ray structures were identified and described by Bürgi and Dunitz in 1975,38 thus revealing the trajectory along which a nucleophile attacks the $\pi$-hole of carbonyl group. More recently, the importance of $\mathrm{n} \rightarrow \pi^{*}$ interactions in proteins from a lone pair of electrons (n) to the antibonding orbital $\left(\pi^{*}\right)$ of the carbonyl group has been demonstrated.39 In addition, operative $\pi$-holes have been described as nitroderivatives, 40-43 group 13 molecules, and acyl carbon containing molecules.44-46 The physical nature and factors affecting the strength of $\pi$-hole interactions are similar to those of $\sigma$-hole interactions.31-36 The significance of these $\pi$-hole interactions has been increasingly recognized in the solid state, and they have been demonstrated by an accurate analysis of experimental electron density maps from X-ray analysis in nitroderivatives, boronic acids, and carboxylic acids.47 In this manuscript, we demonstrate that the eight-membered supramolecular ring R2 2 (8) that is formed upon dimerization of benzoic acids is an overlooked synthon that has a marked tendency to establish ditopic $\pi$-hole interactions with electron rich atoms. We use the Cambridge Structural Database (CSD)48 to demonstrate the ability of carboxylic acid dimeric entities to form donor-acceptor interactions involving $\pi$-holes located at the $\mathrm{C}$ atoms above and below the molecular plane. Moreover, we have carried out DFT calculations (PBE0-D3/def2-TZVP) to investigate the geometric and energetic features of these interactions and how they are influenced by additional substituents of the benzoic aromatic ring. Finally, to support this unnoticed behavior and to use it in a predictive way, we report the 
102 synthesis and X-ray characterization of a solvate of gallic acid with dioxane, where two molecules of 103 dioxane are located above and below the eight-membered supramolecular ring, forming two 104 symmetrically equivalent $\mathrm{O} \cdots \mathrm{C} \pi$-hole interactions.

105

106 
109 Synthesis and X-ray Details. Suitable single crystals of gallic acid/dioxane solvate for X-ray diffraction

110 analysis were obtained by slow recrystallization of a solution of gallic acid in dioxane at room

111 temperature.

112 Single crystal X-ray diffraction intensity data were collected using a D8 Venture system equipped with a 113 multilayer monochromator and a Mo microfocus $(\lambda=0.71073 \AA)$. Frames were integrated with the

114 Bruker SAINT software package using a SAINT algorithm. Data were corrected for absorption effects

115 using the multiscan method (SADABS).49 The structure was solved and refined using the Bruker

116 SHELXTL Software Package, a computer program for automatic solution of crystal structures and

117 refined by full-matrix least-squares method with ShelXle Version 4.8.0, a Qt graphical user interface for

118 SHELXL computer program.50

119 Theoretical Methods. The energies of all complexes included in this study were computed at the 120 PBE051,52-D353/def2-TZVPD54,55 level of theory by means of the program TURBOMOLE version 121 7.0.56 The interaction energies have been computed using the formula $\Delta \mathrm{E}=\mathrm{E}(\mathrm{a})-\mathrm{E}(\mathrm{b})-2 \mathrm{E}(\mathrm{c})$, where $122 \mathrm{E}(\mathrm{a})$ is the energy of the assembly, $\mathrm{E}(\mathrm{b})$ is the energy of the optimized supramolecular R2 2 (8) dimer, 123 and $\mathrm{E}(\mathrm{c})$ is the energy of the optimized Lewis base. The MEP (molecular electrostatic potential)

124 calculations have been performed at the PBE0-D3/def2-TZVP level of theory by means of the Gaussian-

12516 calculation package.57 The Bader's “Atoms in Molecules" theory58 has been used to study the

126 interactions discussed herein by means of the AIMall calculation package.59 
Preliminary MEP Calculations. As aforementioned, a $\sigma / \pi$-hole is a region of the molecule where the electronic density is lower than its surroundings (commonly a positive electrostatic potential). Through this positive potential, the molecule can interact attractively with nucleophiles, such as lone pairs, $\pi$ electrons, and anions. Thus, we have first computed the molecular electrostatic potential (MEP) plotted onto the van der Waals surface of the benzoic acid dimer that is represented in Figure 1. It can be observed that the eight-membered supramolecular ring presents two equivalent $\pi$-holes above and below the $\mathrm{C}$ atoms of the carboxylate groups $(+10 \mathrm{kcal} / \mathrm{mol})$. Moreover, the MEP is also positive over the center of the supramolecular ring. The negative part corresponds to the $\mathrm{O}$ atoms of the carbonyl groups at the molecular plane $(-30 \mathrm{kcal} / \mathrm{mol})$. The MEP surface evidence shows that the supramolecular ring that is generated by the dimerization of carboxylic acids has the potential ability to attract electron rich atoms and establish $\pi$-hole interactions.

CSD Analysis. The Cambridge Structural Database is a large depot of geometrical information that offers the opportunity to reveal interactions that have been unnoticed by the original authors. Therefore, we have used the CSD to analyze the ability of aromatic carboxylic acid dimers to establish $\pi$-hole interactions. The fragment used in the search is represented in Figure 2a, where the electron rich atom used is oxygen. We have used aromatic rings in order to minimize steric effects that could influence the location of the lone pair (lp) donor. Moreover, the aromatic ring does not present substituents in both ortho-positions to ensure the coplanarity of the carboxylic group with the aromatic ring. We have retrieved those structures where the $\mathrm{O} \cdots \mathrm{C}$ distance (d) is shorter than $5 \AA$. In order to ensure that the electron rich atom is located above and below the molecular plane, we have defined the angle $(\beta)$ between the planes denoted as P1 and P2 in Figure 2a, where P1 is the molecular mean plane and P2 is the plane defined by the atom of $\mathrm{O}$ and the exocyclic $\mathrm{C}-\mathrm{COOH}$ bond. In addition, to select those structures where the electron donor $\mathrm{O}$ atom is located approximately over the $\pi$-hole, we have only selected those structures where the $\mathrm{O} \cdots \mathrm{C} \cdots \mathrm{X}$ angle $\alpha$ is comprised between $75^{\circ}$ and $105^{\circ}$. In the case where a large angle is defined, the $\mathrm{O}$ atom is allowed to reach the $\pi$-system, and consequently, hits corresponding to $\mathrm{lp}-\pi$ interactions could be retrieved. If a smaller angle is used, the $\mathrm{O}$ atom is allowed to interact with the other $\pi$-hole of the R2 2 (8) ring, thus invalidating the analysis (duplicates could be retrieved for long d values). Finally, we have used "only organics," "no errors," and "no disorder" options in the CSD software conquest60 and X-ray determined structures (no powder structures). As a result, we have found 977 fragments in the CSD exhibiting $\mathrm{O} \cdots \pi$-hole distances shorter than $5 \AA$ that correspond to $634 \mathrm{X}$-ray structures, in good agreement with the preliminary MEP surface results. The parameter $\alpha$ is a good indicator of the location of the $\mathrm{O}$ atom, since values close to $90^{\circ}$ (in combination with the $\beta$ constrain) indicate that the oxygen atom is precisely over the $\pi$-hole. The scattergram represented in Figure $2 \mathrm{~b}$ shows a concentration of points at values of $\alpha$ between 90 and $100^{\circ}$ and distances close to the sum of van der Waals radii $(\Sigma \mathrm{RvdW})$. This likely indicates a directionality of the 
interaction (the $\mathrm{O}$ atom is located over the $\pi$-hole at $\Sigma \mathrm{RvdW}$ distance). The directionality is also suggested by the histogram shown in Figure 2d, where the major number of hits (294) is observed in the $95^{\circ}-100^{\circ}$ range. The histogram shown in Figure $2 \mathrm{c}(\mathrm{O} \cdots \pi-$ hole distance $)$ also shows that a large number of structures (457) present distances close to the $\Sigma \mathrm{RvdW}(3.22 \AA)$. In fact, the percentage of fragments with distances shorter than $\Sigma \mathrm{RvdW}$ is $25.5 \%$ of the total, and if the limit to consider a contact is enlarged to $\Sigma \mathrm{RvdW}+0.2 \AA$, the ratio increases to $70.8 \%$. This analysis clearly highlights that the centrosymmetric H-bonded carboxylic dimer supramolecular ring is well suited to establish $\pi$-hole interactions.

We have manually inspected the solid state architecture and crystal packing of the hits obtained from the search described above with distances shorter than $\Sigma \mathrm{RvdW}+0.2 \AA$. Agreeably, the analysis of the structures revealed that the carboxylic acid dimer usually participates in two symmetrically related $\pi$-hole interactions, above and below the molecular plane (232 out of 497 structures). We have represented four structures in Figure 3 where different O-donor groups are involved in the interaction. Figure 3a shows the structure of p-methylsulfonylbenzoic acid (refcode COBFUU61) where the centrosymmetric hydrogen-bonded carboxylic acid dimer establishes two $\mathrm{O} \cdots \pi-$ hole interactions. In this self-assembly, the $\mathrm{O}$ atoms of the sulfonyl groups are located at $3.11 \AA(0.11 \AA$ shorter than $\Sigma \mathrm{RvdW})$ from the carboxylic $\mathrm{C}$ atoms and pointing to the $\pi$-hole $\left(\alpha=81.4^{\circ}\right)$.

We have selected a picrate salt [7-carboxy-2,4-dimethyl-5Hbenzo(b)(1,4)diazepinium picrate] as an example of interaction where the $\mathrm{O}$ atom is anionic (refcode UMUXIJ62). Interestingly, the cationic part self-assembles, forming the Hbonded dimer that establishes two symmetrically equivalent and highly directional $\left(\alpha=88.3^{\circ}\right) \mathrm{O}-\cdots \pi$-hole interactions. Two additional structures, 3,5-dinitrobenzoic acid and the cocrystal of 3-hydroxybenzoic acid and 5-fluoropyrimidine- 2,4(1H,3H)-dione (refcodes CUKCAM2563 and IQIKUQ,64 respectively), are represented in Figure 3c,d. In these structures, the $\pi$-hole interactions are established between the $\mathrm{H}$-bonded carboxylic dimer and electron rich $\mathrm{O}$ atoms belonging to nitro and carbonyl groups (see Figure 3c,d). In Figure 3, we have also represented, as red dashed lines, additional interactions observed in the crystal structures that also influence the final geometry of the supramolecular assemblies. For COBFUU and IQICUK structures, $\pi$-stacking interactions are also established between the H-bonded dimer and the aromatic ring of the O-donor molecule. Remarkably, in UMUJIJ and CUKCAM25 structures, additional $\mathrm{O} \cdots \pi$-hole interactions are also established, in the former with the $\pi$-hole of the adjacent carboxylate $(3.13 \AA)$ and in the latter with the $\pi$-hole of the nitro group $(3.05 \AA)$.

Theoretical Study. In order to analyze the geometric and energetic features of $\pi$-hole interactions involving the RCOOH $\cdots$ HOOCR synthon, the R2 2 (8) ring, we have initially computed dimers 1-6 and their complexes 7-18 as shown in Figure 4. They correspond to double $\pi$-hole complexes where the electron donor is either dimethyl ether or acetone, and we have incorporated different substitution in the aromatic rings. Therefore, the interaction energies listed in Table 1 correspond to 1:2 ternary complexes where the R2 2 (8) ring interacts with two Lewis acids. From the inspection of the results gathered in 
Table 1, several interesting issues arise. First, the ability of carboxylic acid H-bonded dimers as double $\pi$-hole donors is confirmed since the optimized geometries are in fact stabilized by the formation of $\mathrm{O} \cdots \pi$-hole interactions. Second, the energies are moderately strong, ranging from -11.5 to -9.9 $\mathrm{kcal} / \mathrm{mol}$, and the equilibrium distances are in all cases slightly shorter than $\Sigma \mathrm{RvdW}$ and similar to those observed experimentally. In all cases, $\alpha$ and $\beta$ angles are close to $90^{\circ}$, thus confirming that the $\mathrm{O}$ atom is located over the $\pi$-hole. Finally, substituent effects are not very significant, likely due to the distance between the electron donor and the substituent. Nevertheless, in each series, the complex involving the p-cyanobenzoic acid dimer 4 is the most favorable (complexes 10 and 16). We have also taken advantage of the DFT calculations to validate the geometric criterion used to analyze the CSD search: we have selected those hits where $\mathrm{d} \leq \Sigma \mathrm{RvdW}+0.20(3.42 \AA)$. We have computed the $\Delta \mathrm{E}$ of complex 7 situating the $\mathrm{O}$ atom exactly at the $\Sigma \mathrm{RvdW}$ and compared it to the one situating the $\mathrm{O}$ atom exactly at the $\Sigma \mathrm{RvdW}+0.20 \AA$. As a result, the interaction energy is only reduced by $24 \%$ by enlarging the distance $0.2 \AA$. Therefore, it can be assumed that $78 \%$ of the structures retrieved from the CSD with $\mathrm{O} \cdots \mathrm{C}$ distances $\leq 5 \AA$ have a significant contribution from the $\mathrm{O} \cdots \pi$-hole interaction. The optimized geometries of some complexes are represented in Figure 5 where the $\mathrm{O} \cdots \pi$-hole interactions are represented using black dashed lines. The conformation adopted by the O-donor molecule in the complexes reveals the existence of two ancillary $\mathrm{C}-\mathrm{H} \cdots \mathrm{O}$ interactions. In the complexes with dimethyl ether, these distances are quite long $(>2.7 \AA)$ and not very directional (the lone pairs of the $\mathrm{O}$ atom are situated in the molecular plane), therefore their contribution to the overall interaction energy is expected to be small. These ancillary $\mathrm{C}-\mathrm{H} \cdots \mathrm{O}$ interactions can be rationalized by the fact that the MEP surface shows negative potential over the $\mathrm{O}$ atoms. For the acetone complexes, these H-bonds are shorter in line with the higher acidity of the $\mathrm{H}$ atoms adjacent to the carbonyl group. These ancillary interactions explain the orientation of the O-donor molecules and also the fact that dimethyl ether and acetone complexes exhibit similar interaction energies. That is, there is a compensation effect between the $\mathrm{O} \cdots \pi$-hole interaction that is stronger (shorter distances) in dimethyl ether complexes 7-12 and the ancillary $\mathrm{C}-\mathrm{H} \cdots \mathrm{O}$ interactions that are stronger in acetone complexes 13-18 (shorter distances). We have carried out Bader's theory of "atoms-in-molecules" analysis of complexes 7-18 in order to corroborate the existence of concurrent $\mathrm{O} \cdots \pi$-hole and $\mathrm{C}-\mathrm{H} \cdots \mathrm{O}$ interactions. The presence of a bond path (lines of maximum density linking neighboring nuclei in a system) and bond critical point connecting two atoms is universal evidence of interaction.65 The distributions of bond CPs and bond paths in four representative complexes are given in Figure 6. The $\mathrm{O} \cdots \pi$-hole interaction is characterized by a bond $\mathrm{CP}$ and bond path interconnecting the $\mathrm{O}$ and $\mathrm{C}$ atoms and confirming the interaction. Each $\mathrm{C}-\mathrm{H} \cdots \mathrm{O}$ interaction is also characterized by a bond $\mathrm{CP}$ and bond path that connect the $\mathrm{H}$ atom to the $\mathrm{O}$ atom of the carboxylic group. It is worth mentioning that the value of charge density $\rho(r)$ at the bond $\mathrm{CP}$ is a good indicator of the strength of the interaction, as demonstrated by a great deal of interactions.66-69 The values of $\rho(r)$ at the bond CPs that characterize the $\pi$-hole interactions in complexes 7-18 are also summarized in Table 1 . They confirm that the $\pi$-hole interactions in the 
complexes with dimethyl ether are stronger compared to the equivalent ones with acetone, in agreement with the equilibrium distances. The $\rho(\mathrm{r})$ is at a maximum in complex 10 that presents a shorter $\mathrm{O} \cdots \pi$-hole distance, confirming that the $\rho(\mathrm{r})$ at the bond $\mathrm{CP}$ is a good indicator of the strength of the interaction. In Figure 6, we include the $\rho(\mathrm{r})$ values at all bond CPs that appear upon complexation. The $\rho(\mathrm{r})$ values at the bond $\mathrm{CPs}$ that characterize the $\mathrm{C}-\mathrm{H} \cdots \mathrm{O}$ interactions are larger in the acetone complexes 13 and 16 than in the corresponding dimethyl ether complexes 7 and 10, in line with the shorter H-bond distances observed in acetone complexes. On the contrary, the values of $\rho(\mathrm{r})$ at the bond CPs that characterize the $\mathrm{O} \cdots \pi$-hole interactions are larger in the dimethyl ether complexes in agreement with the equilibrium distances and the higher Lewis basicity character of dimethyl ether compared to acetone. In order to confirm that the $\mathrm{O} \cdots \pi$-hole interaction dominates the formation of the complexes, we have computed two additional complexes (19 and 20, see Figure 4) where the dimethyl ether has been replaced by hexafluorodimethyl ether. In particular, we have used compounds 1 and 4 as $\pi$-hole donors. The energetic and geometric features of both complexes are also included in Table 1, and the geometry of the complexes is shown in Figure S1 (Supporting Information, SI). In spite of the electron donor character of the $\mathrm{O}$ atom being reduced in $\mathrm{CF} 3 \mathrm{OCF} 3$ compared to dimethyl ether due to the strong electron-withdrawing effect, the interaction energies of complexes 19 and 20 are still important $(-8.4$ and $-8.6 \mathrm{kcal} / \mathrm{mol}$, respectively). Taking into consideration that the interaction energies using dimethyl ether are -10.2 and $-11.3 \mathrm{kcal} / \mathrm{mol}$, we conclude that the $\mathrm{O} \cdots \pi$-hole interaction is the dominant force in these complexes. Finally, we have also carried out the AIM analyses of complexes 19 and 20, which are represented in Figure S2 (see SI), in order to discard a possible contribution from F $\cdots \mathrm{H}$ interactions in these complexes. As a result, they do not show any bond path connecting the $\mathrm{F}$ atoms to the $\mathrm{H}$ atoms belonging to the R2 2 (8) ring, indicating that there is not any contribution from F $\cdots \mathrm{H}$ contacts. This is likely due to the fact that these $\mathrm{H}$ atoms are involved in strong $\mathrm{H}$-bonding interactions. Instead, the AIM analysis shows that the $\mathrm{F}$ atoms are connected to the $\mathrm{O}$ atoms of the $\mathrm{R} 22$ (8) ring, thus suggesting the contrary effect (possible repulsion between the $\mathrm{O}$ atoms and the $\mathrm{F}$ atoms of perfluorodimethyl ether).

Experimental Results. Encouraged by the aforementioned results from the CSD and DFT calculations, we envisaged utilizing gallic acid in combination with a ditopic $\mathrm{O}$ atom donor to generate a solid-state architecture where double $\pi$-hole interactions could be established. That is, the combination of a double O-donor molecule with a double $\pi$-hole donor can be a good crystal engineering strategy to influence the crystal packing by taking advantage of the ability of the carboxylic acid dimer to establish this particular interaction. Gratifyingly, we succeeded in the cocrystallization of gallic acid and dioxane. This solvate crystallizes in the $\mathrm{P}[$ space group, and the asymmetric unit (shown in Figure 7) is composed by three independent units of dioxane (two half molecules and one complete molecule) and one of gallic acid.

276 A partial view of the crystal packing is shown in Figure 8 where, as expected, the centrosymmetric 
278 dimers by means of two $\mathrm{O} \cdots \pi$-hole interactions involving the axial lone pairs. The equatorial lone pairs

279 form $\mathrm{O}-\mathrm{H} \cdots \mathrm{O}$ interactions with the hydroxyl group in para belonging to the gallic acid. The $\alpha$ and $\beta$

280 angles (see Figure 2 for their definition) are close to $90^{\circ}$, thus confirming the directionality of the

281 interaction. This result clearly confirms the potential use of carboxylic acid dimers as templates for

$282 \mathrm{O} \cdots \pi$-hole interactions to be exploited in crystal engineering. Other interactions are also observed in the

283 solid state of the cocrystal like $\pi-\pi$ stacking interactions that are also important to understand the crystal

284 packing (marked using red dashed lines in Figure 8). Finally, to estimate the relative importance of the

$285 \mathrm{O} \cdots \pi$-hole interaction, we have computed the binding energy of the supramolecular assembly that is

286 formed by the gallic acid self-assembled H-bonded R2 2 (8) dimer and two dioxane molecules above

287 and below the molecular plane using the X-ray coordinates (see Figures S3). The resulting interaction

288 energy is $-10.5 \mathrm{kcal} / \mathrm{mol}$, which is in quite good agreement with the optimized complex 12 (gallic acid

289 dimer with two dimethyl ether molecules). This supports the fact that the location of the dioxane

290 molecules in the X-ray structure is due, among other factors like H-bonds and $\pi$-stacking interactions, to

291 the formation of the $\mathrm{O} \cdots \pi$-hole interactions. 


\section{CONCLUSIONS}

294

295 In this work, we have demonstrated for the first time that the centrosymmetric double H-bond

296 carboxylic dimer has a strong ability to establish two simultaneous $\pi$-hole interactions. We have shown

297 that a large number of X-ray structures in the CSD exhibit this type of interaction that determines the

298 formation of a robust supramolecular synthon. The interaction is moderately strong as evidenced by

299 DFT calculations. Finally, based on this previous knowledge, we have envisaged the cocrystallization of

300 a gallic acid with a double O-donor (dioxane) to support the robustness of this synthon. We succeeded in

301 the synthesis of the solvate that exhibited, as rationally predicted, self-assembled H-bonded carboxylic

302 dimers connected by the ditopic electron donor. We consider that the results reported herein may

303 function as useful empirical principles of $\pi$-hole interactions in crystal engineering and supramolecular

304 chemistry, where these interactions are increasingly recognized as functionally relevant.

305 


\section{AUTHOR INFORMATION}

307

308 *E-mail: rafel@ccit.ub.edu.

309 *E-mail: toni.frontera@uib.es.

310 ORCID

311 Rafel Prohens: 0000-0003-0294-1720

312 Antonio Franconetti: 0000-0002-7972-8795

313 Antonio Frontera: 0000-0001-7840-2139

314 Author Contributions

315 The manuscript was written through contributions of all authors. All authors have given approval to the

316 final version of the manuscript.

317 Notes

318 The authors declare no competing financial interest.

319

320 


\section{ACKNOWLEDGEMENTS}

322

323 We thank the DGICYT of Spain (project CTQ2017-85821-R FEDER funds). We thank the CTI (UIB)

324 for computational facilities. A.F. thanks MINECO/AEI from Spain for a "Juan de la Cierva" contract.

325 
(1) Desiraju, G. R. Crystal Engineering: The Design of Organic Solids; Elsevier: Amsterdam, 1989.

(2) Saha, S.; Desiraju, G. R. $\sigma$-Hole and $\pi$-Hole Synthon Mimicry in Third-Generation Crystal

(3) Ghosh, S.; Reddy, C. M. Elastic and Bendable Caffeine Cocrystals: Implications for the Design of Flexible Organic Materials. Angew. Chem., Int. Ed. 2012, 51, 10319-10323.

(4) Ghosh, S.; Mishra, M. K.; Kadambi, S. B.; Ramamurty, U.; Desiraju, G. R. Designing elastic

(5) Gilli, G.; Gilli, P. The Nature of the Hydrogen Bond; Oxford University Press: Oxford, 2009.

(6) Desiraju, G. R.; Steiner, T. The Weak Hydrogen Bond in Structural Chemistry and Biology; Oxford University Press: Oxford, 1999.

(9) Clark, T. $\sigma$-Holes. WIREs Comput. Mol. Sci. 2013, 3, 13-20.

(10) Wozniak, K.; Mallinson, P. R.; Wilson, C. C.; Hovestreydt, E.; Grech, E. Charge Density Studies of Weak Interactions in Dipicrylamine. J. Phys. Chem. A 2002, 106, 6897-6903.

(11) Bauzá, A.; Mooibroek, T. J.; Frontera, A. The Bright Future of Unconventional $\sigma / \pi$-Hole Interactions. ChemPhysChem 2015, 16, 2496-2517.

(12) Thakur, T. S.; Kirchner, M. T.; Blaser, D.; Boese, R.; Desiraju, G. R. Nature and strength of $\mathrm{C}-\mathrm{H} \cdots \mathrm{O}$ interactions involving formyl hydrogen atoms: computational and experimental studies of small aldehydes. Phys. Chem. Chem. Phys. 2011, 13, 14076-14091.

(13) Saritemur, G.; Nomen Miralles, L.; Husson, D.; Pitak, M. B.; Coles, S. J.; Wallis, J. D. Two modes of peri-interaction between an aldehyde group and a carboxylate anion in naphthalaldehydate salts. CrystEngComm 2016, 18, 948-961. 
(14) Mukherjee, A.; Desiraju, G. R. Halogen bonds in some dihalogenated phenols: applications to crystal engineering. IUCrJ 2014, 1, 49-60.

(15) Cavallo, G.; Metrangolo, P.; Milani, R.; Pilati, T.; Priimagi, A.; Resnati, G.; Terraneo, G. The Halogen Bond. Chem. Rev. 2016, 116, 2478-2601.

(16) Del Bene, J. E.; Alkorta, I.; Elguero, J. In The Pnicogen Bond in Review: Structures, Energies, Bonding Properties, and Spin-Spin Coupling Constants of Complexes Stabilized by Pnicogen Bonds; Scheiner, S., Ed.; Springer: Dordrecht, 2015; Vol. 19, pp 191-263.

(17) Politzer, P.; Murray, J. S. In A Unified View of Halogen Bonding, Hydrogen Bonding and Other б-Hole Interactions; Scheiner, S., Ed.; Springer: Dordrecht, 2015; Vol. 19, pp 357-389.

(18) Murray, J. S.; Lane, P.; Clark, T.; Riley, K. E.; Politzer, P. $\Sigma$-holes, $\pi$-holes and electrostatically-driven interactions. J. Mol. Model. 2012, 18, 541-548.

(19) Politzer, P.; Murray, J. S. $\sigma$-holes and $\pi$-holes: Similarities and differences. J. Comput. Chem. $2018,39,464-471$.

(20) Kolář, M. H.; Hobza, P. Computer Modeling of Halogen Bonds and Other $\sigma$-Hole Interactions. Chem. Rev. 2016, 116, 5155-5187.

(21) Zierkiewicz, W.; Wieczorek, R.; Hobza, P.; Michalska, D. Halogen bonded complexes between volatile anaesthetics (chloro-form, halothane, enflurane, isoflurane) and formaldehyde: a theoretical study. Phys. Chem. Chem. Phys. 2011, 13, 5105-5113.

(22) Riley, K. E.; Ford, C. L., Jr.; Demouchet, K. Comparison of hydrogen bonds, halogen bonds, $\mathrm{CH}^{\cdots} \pi \pi$ interactions, and $\mathrm{CX} \cdots \pi$ interactions using high-level ab initio methods. Chem. Phys. Lett. 2015, 621, 165-170.

(23) Scheiner, S. Effects of multiple substitution upon the P $\cdots \mathrm{N}$ noncovalent interaction. Chem. Phys. 2011, 387, 79-84.

(24) Adhikari, U.; Scheiner, S. Effects of Charge and Substituent on the S $\cdots$ N Chalcogen Bond. J. Phys. Chem. A 2014, 118, 3183-3192.

(25) Zierkiewicz, W.; Bienko, D. C.; Michalska, D.; Zeegers- Huyskens, T. Theoretical investigation of the halogen bonded complexes between carbonyl bases and molecular chlorine. J. Comput. Chem. 2015, 36, 821-832. 
(26) Southern, S. A.; Bryce, D. L. NMR Investigations of Noncovalent Carbon Tetrel Bonds. Computational Assessment and Initial Experimental Observation. J. Phys. Chem. A 2015, 119, $11891-11899$.

(27) Southern, S. A.; Errulat, D.; Frost, J. M.; Gabidullin, B.; Bryce, D. L. Prospects for 207Pb solidstate NMR studies of lead tetrel bonds. Faraday Discuss. 2017, 203, 165-186.

(28) Bauzá, A.; Mooibroek, T. J.; Frontera, A. Tetrel-Bonding Interaction: Rediscovered Supramolecular Force? Angew. Chem., Int. Ed. 2013, 52, 12317-12321.

(29) Bauzá, A.; Frontera, A. Aerogen Bonding Interaction: A New Supramolecular Force? Angew. Chem., Int. Ed. 2015, 54, 7340-7343.

(30) Bauzá, A.; Mooibroek, T. J.; Frontera, A. Directionality of $\pi$-holes in nitro compounds. Chem. Commun. 2015, 51, 1491-1493.

(31) Wang, H.; Wang, W.; Jin, W. J. $\sigma$-Hole Bond vs $\pi$-Hole Bond: A Comparison Based on Halogen Bond. Chem. Rev. 2016, 116, 5072-5104.

(32) Sure, R.; Grimme, S. Halogen bonded supramolecular capsules: a challenging test case for quantum chemical methods. Chem. Commun. 2016, 52, 9893-9896.

(33) Politzer, P.; Murray, J. S.; Clark, T. Halogen bonding and other $\sigma$-hole interactions: a perspective. Phys. Chem. Chem. Phys. 2013, 15, 11178-11189.

(34) Politzer, P.; Murray, J. S. Halogen bonding: an interim discussion. ChemPhysChem 2013, 14, 278-294.

(35) Politzer, P.; Murray, J. S.; Clark, T. Halogen bonding: an electrostatically-driven highly directional noncovalent interaction. Phys. Chem. Chem. Phys. 2010, 12, 7748-7757.

(36) Li, W.; Zeng, Y.; Li, X.; Sun, Z.; Meng, L. Insight into the pseudo $\pi$-hole interactions in the M3H6 $\cdots(\mathrm{NCF}) \mathrm{n}(\mathrm{M}=\mathrm{C}, \mathrm{Si}, \mathrm{Ge}, \mathrm{Sn}, \mathrm{Pb} ; \mathrm{n}=1,2,3)$ complexes. Phys. Chem. Chem. Phys. 2016, 18, 24672-24680.

(37) Murray, J. S.; Lane, P.; Clark, T.; Riley, K. E.; Politzer, P. $\sigma$-holes, $\pi$-holes and electrostatically-driven interactions. J. Mol. Model. 2012, 18, 541-548.

(38) Burgi, H. B. Stereochemistry of reaction paths as determined from crystal-structure data relationship between structure and energy. Angew. Chem., Int. Ed. Engl. 1975, 14, 460-473. 
(39) Bartlett, G. J.; Choudhary, A.; Raines, R. T.; Woolfson, D. N. $n \rightarrow \pi^{*}$ interactions in proteins. Nat. Chem. Biol. 2010, 6, 615-620.

(40) Bauza, A.; Frontera, A.; Mooibroek, T. J. $\pi$-Hole interactions involving nitro compounds: Directionality of nitrate esters. Cryst. Growth Des. 2016, 16, 5520-5524.

(41) Bauza, A.; Sharko, A. V.; Senchyk, G. A.; Rusanov, E. B.; Frontera, A.; Domasevitch, K. V. $\pi$ Hole interactions at work: Crystal engineering with nitro-derivatives. CrystEngComm 2017, 19, 1933-1937.

(42) Bauza, A.; Frontera, A.; Mooibroek, T. J. NO3 - anions can act as Lewis acid in the solid state. Nat. Commun. 2017, 8, No. 14522.

(43) Mooibroek, T. J. Coordinated nitrate anions can be directional $\pi$-hole donors in the solid state: A CSD study. CrystEngComm 2017, 19, 4485-4488.

(44) Grabowski, S. J. Triel Bonds, $\pi$-Hole- $\pi$-Electrons Interactions in Complexes of Boron and Aluminium Trihalides and Trihydrides with Acetylene and Ethylene. Molecules 2015, 20, $11297-11316$.

(45) Grabowski, S. J. Two faces of triel bonds in boron trihalide complexes. J. Comput. Chem. 2018, $39,472-480$.

(46) Dutta, D.; Nath, H.; Frontera, A.; Bhattacharyya, M. K. A novel oxalato bridged supramolecular ternary complex of $\mathrm{Cu}(\mathrm{II})$ involving energetically significant $\pi$-hole interaction: Experimental and theoretical studies. Inorg. Chim. Acta 2019, 487, 354-361.

(47) Escudero-Adán, E.; Bauzá, A.; Lecomte, C.; Frontera, A.; Ballester, P. Boron triel bonding: a weak electrostatic interaction lacking electron-density descriptors. Phys. Chem. Chem. Phys. 2018, 20, 24192-24200.

(48) Groom, C. R.; Bruno, I. J.; Lightfoot, M. P.; Ward, S. C. The Cambridge Structural Database. Acta Crystallogr., Sect. B: Struct. Sci., Cryst. Eng. Mater. 2016, B72, 171-179.

(49) SADABS; Bruker AXS: Madison, WI, 2004. SAINT, Software Users Guide, Version 6.0; Bruker Analytical X-ray Systems: Madison, WI, 1999. Sheldrick, G. M. SADABS v2.03: Area-Detector Absorption Correction; University of Göttingen: Germany, 1999. SAINT, version 7.60A; Bruker AXS, 2008. SADABS, v. 2008-1; University of Göttingen: Germany, 2008. 
(50) Sheldrick, G. M. A short history of SHELX. Acta Crystallogr., Sect. A: Found. Crystallogr. 2008, A64, 112-122.

(51) P erdew, J. P.; Burke, K.; Ernzerhof, M. Generalized Gradient Approximation Made Simple. Phys. Rev. Lett. 1996, 77, 3865-3868.

(52) Perdew, J. P.; Ernzerhof, M.; Burke, K. Rationale for mixing exact exchange with density functional approximations. J. Chem. Phys. 1996, 105, 9982-9985.

(53) Grimme, S. Semiempirical GGA-type density functional constructed with a long-range dispersion correction. J. Comput. Chem. 2006, 27, 1787-1799. (b) Grimme, S.; Antony, J.; Ehrlich, S.; Krieg, H. A consistent and accurate ab initio parametrization of density functional dispersion correction (DFT-D) for the 94 elements H-Pu. J. Chem. Phys. 2010, 132, 154104.

(54) Rappoport, D.; Furche, F. Property-optimized Gaussian basis sets for molecular response calculations. J. Chem. Phys. 2010, 133, 134105.

(55) Weigend, F.; Ahlrichs, R. Balanced basis sets of split valence, triple zeta valence and quadruple zeta valence quality for H to Rn: Design and assessment of accuracy. Phys. Chem. Chem. Phys. 2005, 7, 3297-3305.

(56) Ahlrichs, R.; Bär, M.; Haser, M.; Horn, H.; Kölmel, C. Electronic structure calculations on workstation computers: The program system turbomole. Chem. Phys. Lett. 1989, 162, 165.

(57) Frisch, M. J.; Trucks, G. W.; Schlegel, H. B.; Scuseria, G. E.; Robb, M. A.; Cheeseman, J. R.; Scalmani, G.; Barone, V.; Petersson, G. A.; Nakatsuji, H.; Li, X.; Caricato, M.; Marenich, A. V.; Bloino, J.; Janesko, B. G.; Gomperts, R.; Mennucci, B.; Hratchian, H. P.; Ortiz, J. V.; Izmaylov, A. F.; Sonnenberg, J. L.; Williams-Young, D.; Ding, F.; Lipparini, F.; Egidi, F.; Goings, J.; Peng, B.; Petrone, A.; Henderson, T.; Ranasinghe, D.; Zakrzewski, V. G.; Gao, J.; Rega, N.; Zheng, G.; Liang, W.; Hada, M.; Ehara, M.; Toyota, K.; Fukuda, R.; Hasegawa, J.; Ishida, M.; Nakajima, T.; Honda, Y.; Kitao, O.; Nakai, H.; Vreven, T.; Throssell, K.; Montgomery, J. A., Jr.; Peralta, J. E.; Ogliaro, F.; Bearpark, M. J.; Heyd, J. J.; Brothers, E. N.; Kudin, K. N.; Staroverov, V. N.; Keith, T. A.; Kobayashi, R.; Normand, J.; Raghavachari, K.; Rendell, A. P.; Burant, J. C.; Iyengar, S. S.; Tomasi, J.; Cossi, M.; Millam, J. M.; Klene, M.; Adamo, C.; Cammi, R.; Ochterski, J. W.; Martin, R. L.; Morokuma, K.; Farkas, O.; Foresman, J. B.; Fox, D. J. Gaussian 16, revision A.03; Gaussian, Inc.: Wallingford, CT, 2016.

(58) Bader, R. F. W. A quantum theory of molecular structure and its applications. Chem. Rev. 1991, 91, 893-928. 
(59) Keith, T. A. AIMAll Version 13.05.06; TK Gristmill Software: Overland Park, KS, 2013.

(60) Bruno, I. J.; Cole, J. C.; Edgington, P. R.; Kessler, M.; Macrae, C. F.; McCabe, P.; Pearson, J.; Taylor, R. New software for searching the Cambridge Structural Database and visualising crystal structures. Acta Crystallogr., Sect. B: Struct. Sci. 2002, B58, 389-397.

(61) Brunvoll, J.; Colapietro, M.; Domenicano, A.; Marciante, C.; Portalone, G.; Hargittai, I. Molecular Structures of p-Methylsulphonylbenzoic Acid and Methylphenylsulphone: Comparison of X-Ray and Electron Diffraction Results. Z. Naturforsch., B: J. Chem. Sci. 1984, $39,607$.

(62) Schmidt, A.; Shilabin, A. G.; Nieger, M. On benzo[b][1,4]-diazepinium-olates, -thiolates and carboxylates as anti-Hückel mesomeric betaines. Org. Biomol. Chem. 2003, 1, 4342-4350.

(63) Simon, F.; Clevers, S.; Gbabode, G.; Couvrat, N.; Agasse-Peulon, V.; Sanselme, M.; Dupray, V.; Coquerel, G. Enhanced Second Harmonic Generation from an Organic Self-Assembled Eutectic Binary Mixture: A Case Study with 3-Nitrobenzoic and 3,5-Dinitrobenzoic Acids. Cryst. Growth Des. 2015, 15, 946-960.

(64) Dai, X.-L.; Li, S.; Chen, J.-M.; Lu, T.-B. Improving the Membrane Permeability of 5Fluorouracil via Cocrystallization. Cryst. Growth Des. 2016, 16, 4430-4438.

(65) Bader, R. F. W. A Bond Path: A Universal Indicator of Bonded Interactions. J. Phys. Chem. A 1998, 102, 7314-7323.

(66) Cubero, E.; Orozco, M.; Luque, F. J. A Topological Analysis of Electron Density in Cation- $-\pi$ Complexes. J. Phys. Chem. A 1999, 103, 315-321.

(67) Garau, C.; Frontera, A.; Quiñonero, D.; Ballester, P.; Costa, A.; Deyà, P. M. A Topological Analysis of the Electron Density in Anion- $\pi$ Interactions. ChemPhysChem 2003, 4, 1344-1348.

(68) Roselló, Y.; Benito, M.; Molins, E.; Barceló-Oliver, M.; Frontera, A. Adenine as a Halogen Bond Acceptor: A combined experimental and DFT study. Crystals 2019, 9, 224.

(69) Galmes, B.; Martínez, D.; Infante-Carrió, M. F.; Franconetti, A.; Frontera, A. Theoretical Ab Initio Study on Cooperativity Effects between Nitro $\pi$-hole and Halogen Bonding Interactions. Chem- PhysChem 2019, 20, 1135-1144. 


\section{Legends to figures}

499 Figure. 1. Molecular electrostatic potential of the benzoic acid dimer plotted onto the van der Waals

500 surface $(0.002 \mathrm{au})$. The MEP value over the $\mathrm{COOH}$ carbon atom is indicated. The encircled region

501 corresponds to the R2 2 (8) ring.

502

503 Figure.2 (a) Fragment used for the CSD search. (b) Scattergram $\alpha(\mathrm{O} \cdots \mathrm{C}-\mathrm{X}$, where $\mathrm{X}$ is the

supramolecular ring centroid) vs $d(\mathrm{O} \cdots \mathrm{C})$. (c) Histogram of $d(\mathrm{O} \cdots \mathrm{C})$. (d) Histogram of $\alpha(\mathrm{O} \cdots \mathrm{C}-\mathrm{X})$.

505

506

Figure.3 Partial view of the X-ray structures of refcodes, COBFUU (a), UMUXIJ (b), CUKCAM25 (c),

and IQIKUQ (d). Distances in A. See Figure 2 for the definition of the angle $\alpha$.

508

509

Figure.4 Dimers 1-6 and complexes 7-20 studied herein.

510

511 Figure.5 Optimized structures of complexes 8 (a), 14 (b), 9 (c), and 15 (d). Distances in $\AA$. The $\pi$-hole and $\mathrm{H}$-bonding interactions are represented by black and blue dashed lines, respectively. A detail of the MEP surface of the carboxylic dimer is shown in the center of the image.

Figure.6 Distribution of bond, ring, and cage critical points (green, yellow, and dark blue spheres, respectively) and bond paths in complexes $7,10,13$, and 16 .

517

Figure.7 Asymmetric unit of compound 21 (solvate of gallic acid and dioxane) showing the full molecules of the three independent units of dioxane.

Figure.8 Crystal packing of compound 21 with indication of the $\mathrm{O} \cdots \pi$-hole interactions. Distance in $\AA$. 

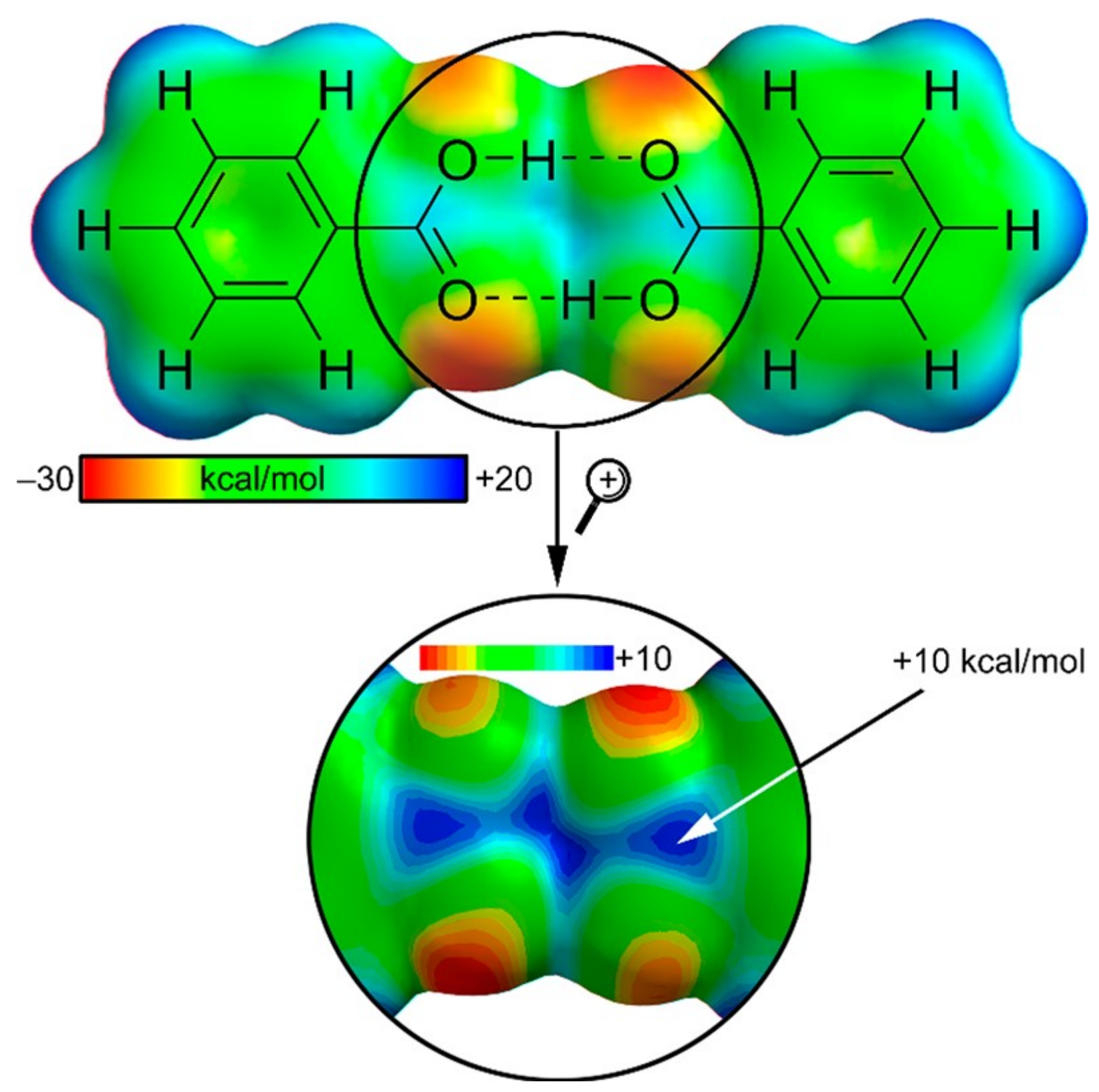


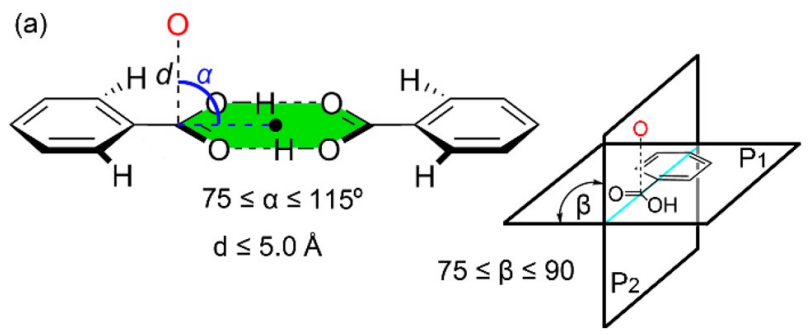

(b)

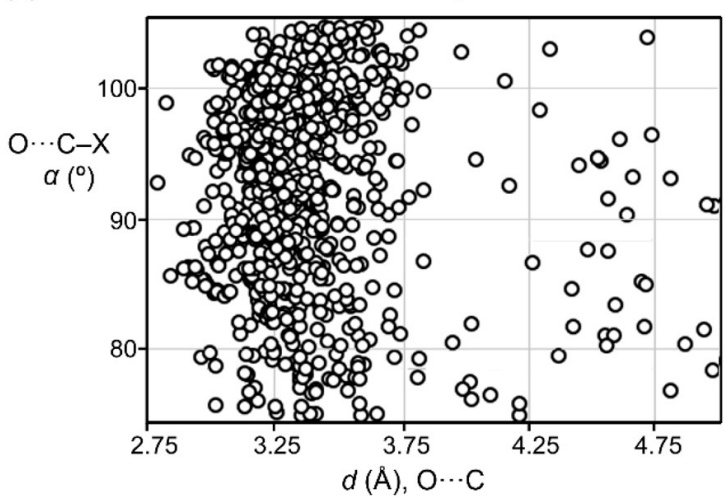

(c)

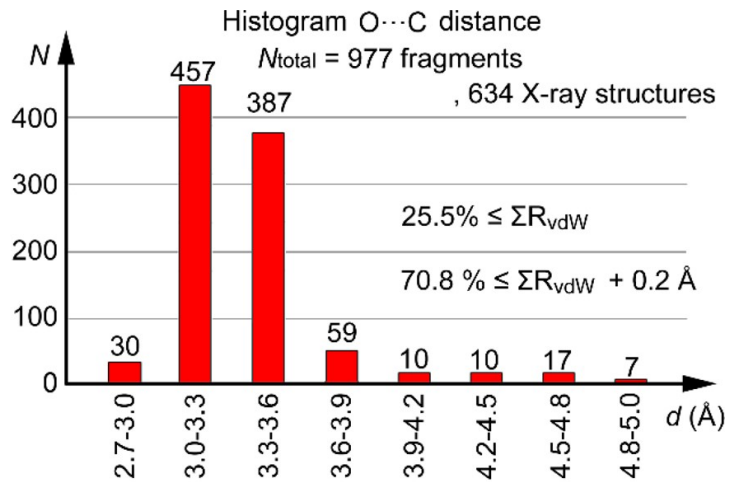

(d)

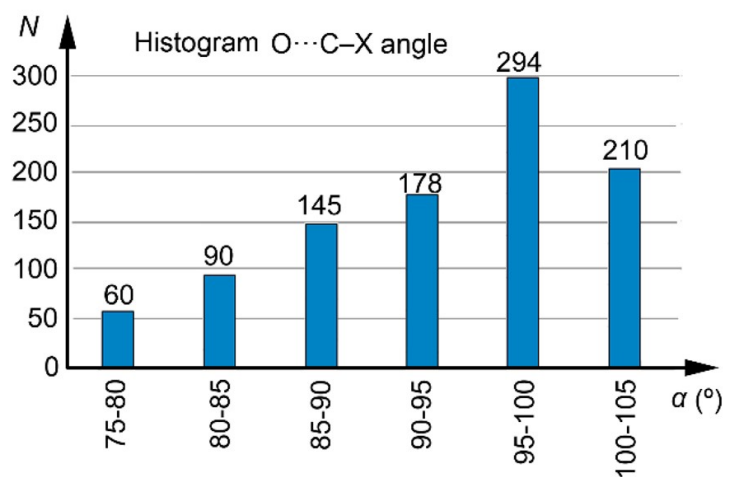



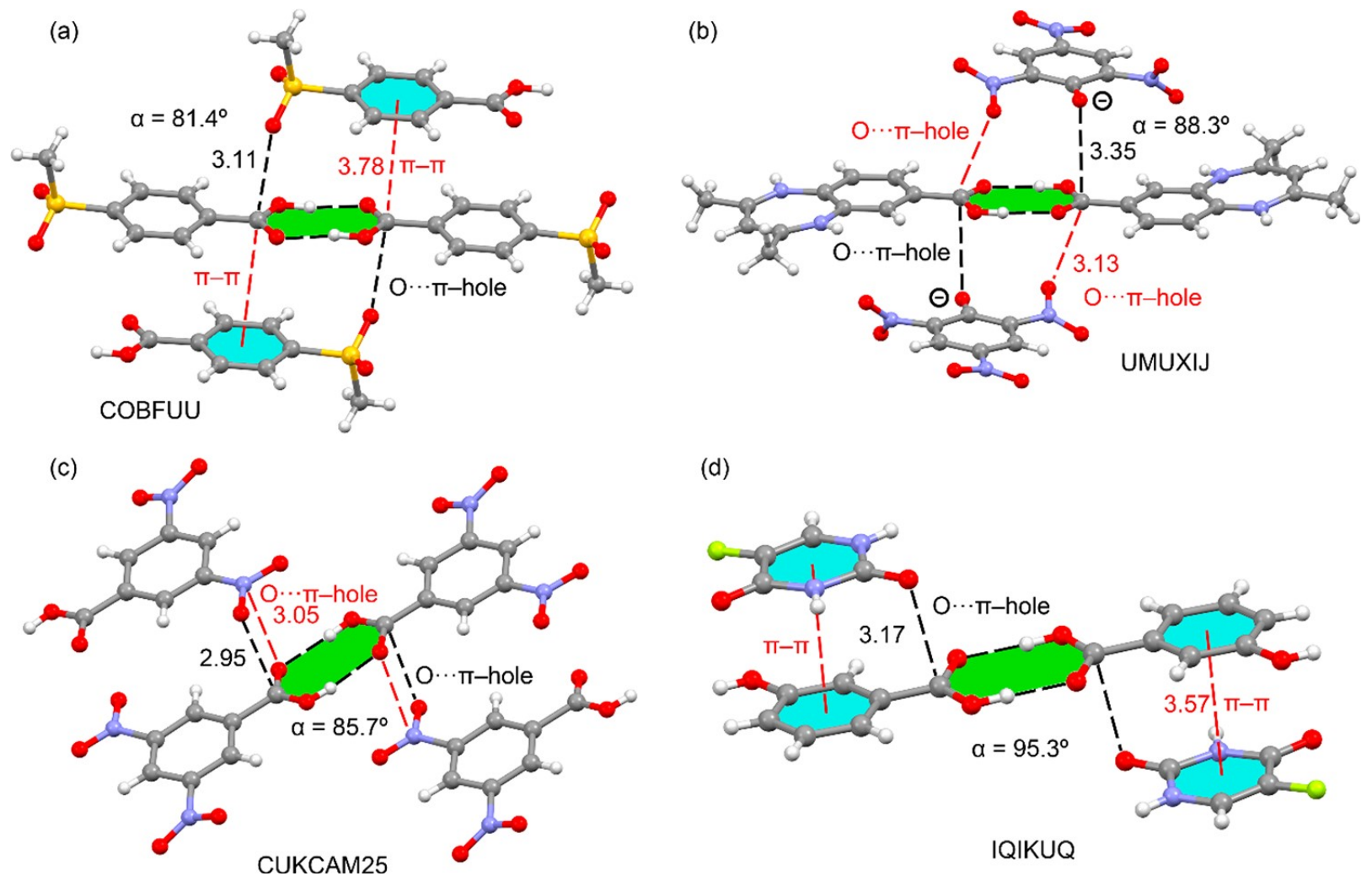

(d)

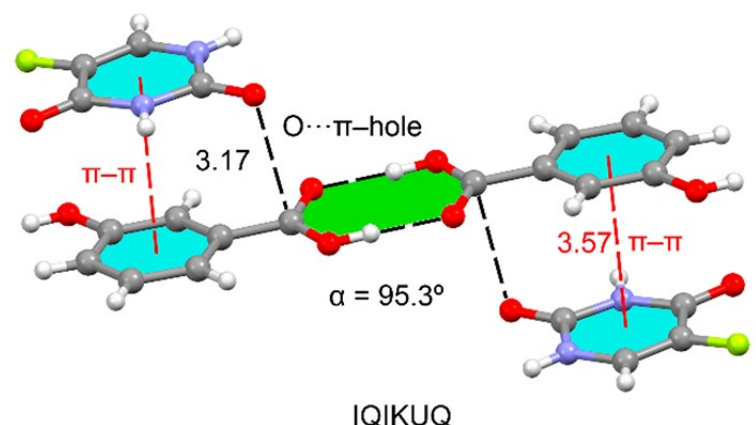


<smiles>[R]c1cc(C(=O)O[CH][IH]OC(=O)c2cc([R])c([R])c([R])c2)cc([R])c1[R]</smiles>

1, $\mathrm{R}^{1}=\mathrm{R}^{2}=\mathrm{R}^{3}=\mathrm{H}$

2, $\mathrm{R}^{1}=\mathrm{OH}, \mathrm{R}^{2}=\mathrm{R}^{3}=\mathrm{H}$

3, $R^{1}=F, R^{2}=R^{3}=H$

4, $\mathrm{R}^{1}=\mathrm{CN}, \mathrm{R}^{2}=\mathrm{R}^{3}=\mathrm{H}$

5, $\mathrm{R}^{1}=\mathrm{OH}, \mathrm{R}^{2}=\mathrm{OH}, \mathrm{R}^{3}=\mathrm{H}$

6, $\mathrm{R}^{1}=\mathrm{OH}, \mathrm{R}^{2}=\mathrm{OH}, \mathrm{R}^{3}=\mathrm{OH}$

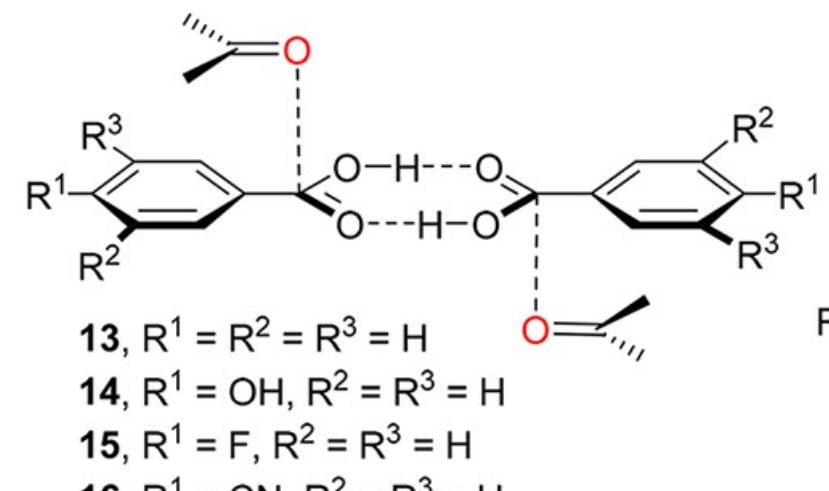

16, $\mathrm{R}^{1}=\mathrm{CN}, \mathrm{R}^{2}=\mathrm{R}^{3}=\mathrm{H}$

17, $\mathrm{R}^{1}=\mathrm{OH}, \mathrm{R}^{2}=\mathrm{OH}, \mathrm{R}^{3}=\mathrm{H}$

543

$18, \mathrm{R}^{1}=\mathrm{OH}, \mathrm{R}^{2}=\mathrm{OH}, \mathrm{R}^{3}=\mathrm{OH}$

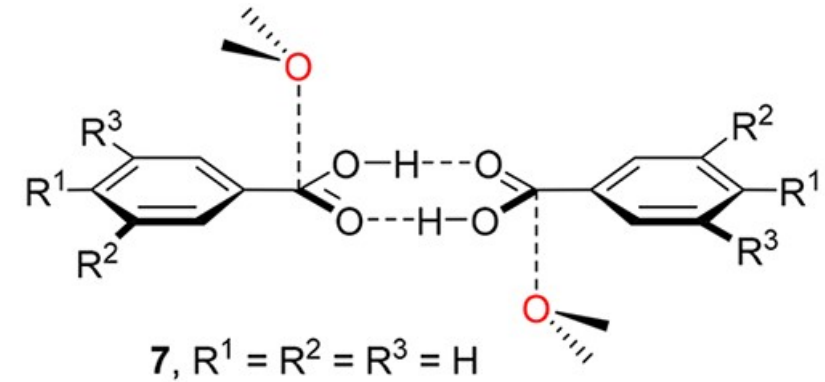

7, $\mathrm{R}^{1}=\mathrm{R}^{2}=\mathrm{R}^{3}=\mathrm{H}$

8, $R^{1}=O H, R^{2}=R^{3}=H$

9, $R^{1}=F, R^{2}=R^{3}=H$

10, $\mathrm{R}^{1}=\mathrm{CN}, \mathrm{R}^{2}=\mathrm{R}^{3}=\mathrm{H}$

$11, \mathrm{R}^{1}=\mathrm{OH}, \mathrm{R}^{2}=\mathrm{OH}, \mathrm{R}^{3}=\mathrm{H}$

12, $\mathrm{R}^{1}=\mathrm{OH}, \mathrm{R}^{2}=\mathrm{OH}, \mathrm{R}^{3}=\mathrm{OH}$

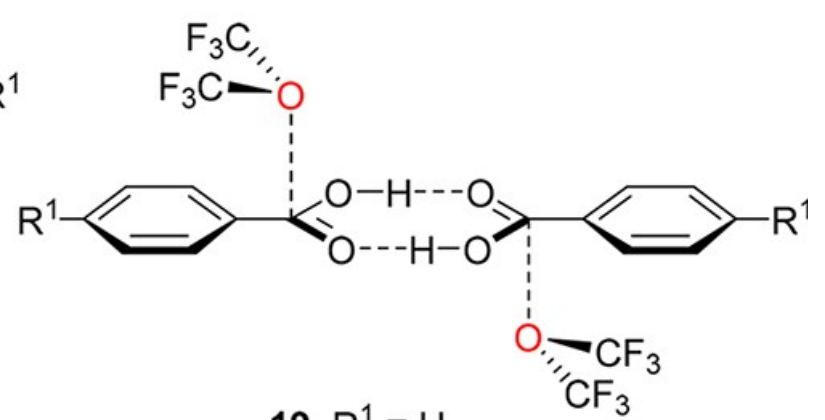

19, $\mathrm{R}^{1}=\mathrm{H}$

20, $\mathrm{R}^{1}=\mathrm{CN}$ 
545

546

547

FIGURE 5
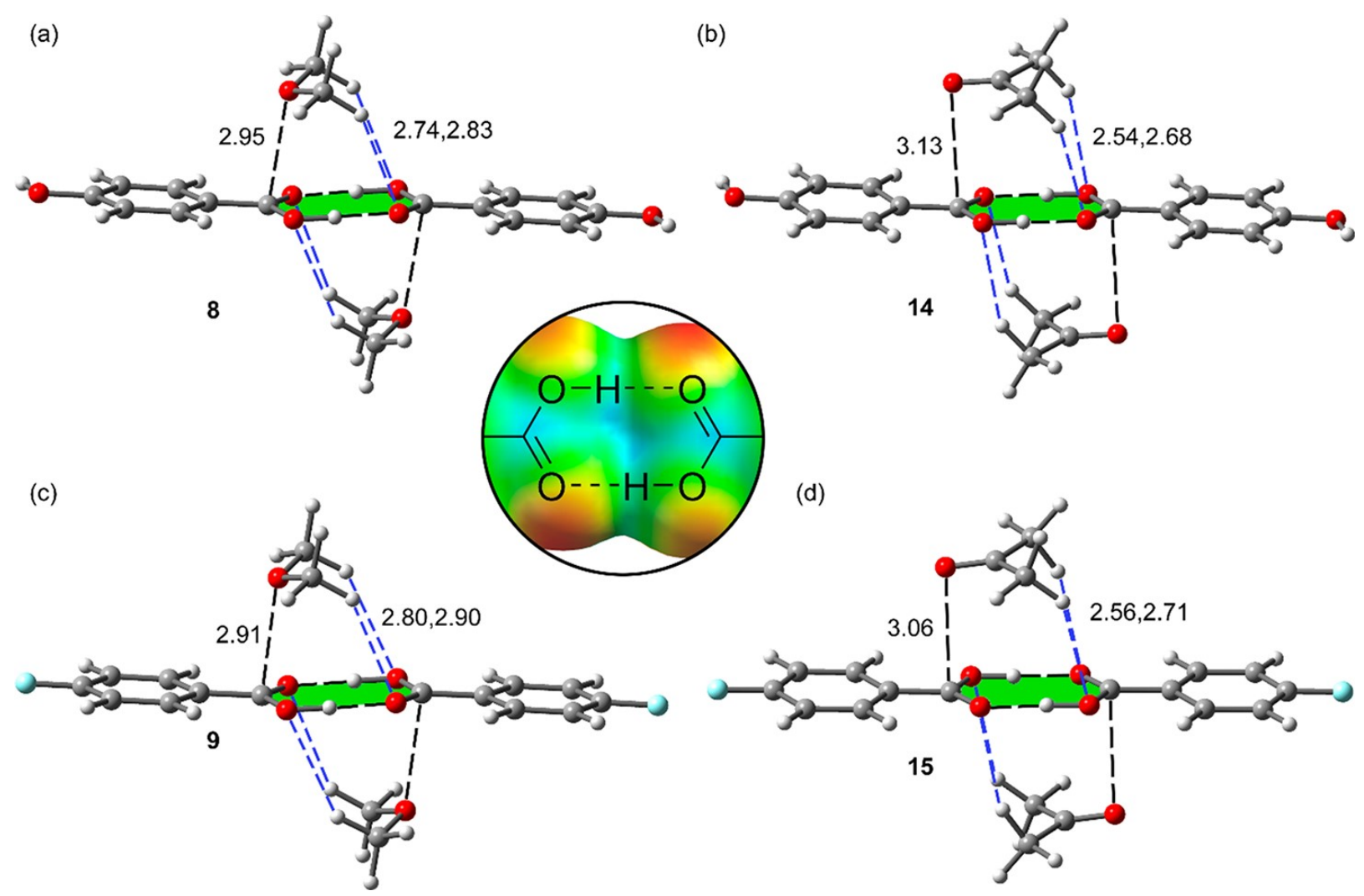

(d)

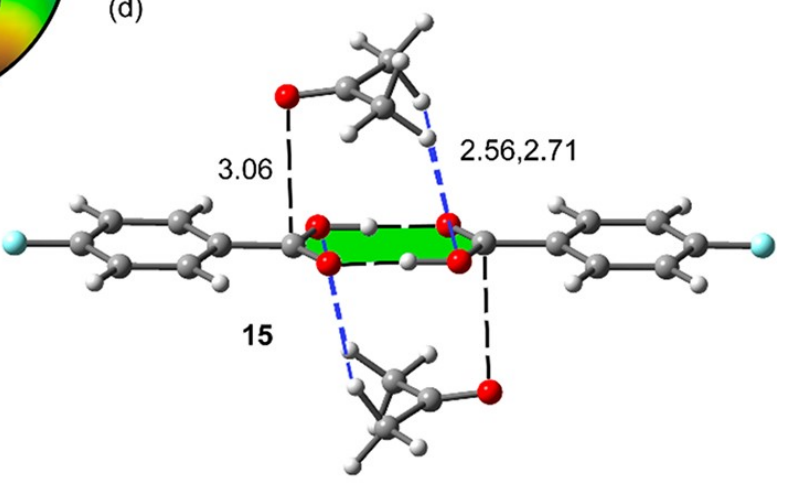


549

550

551

(a)

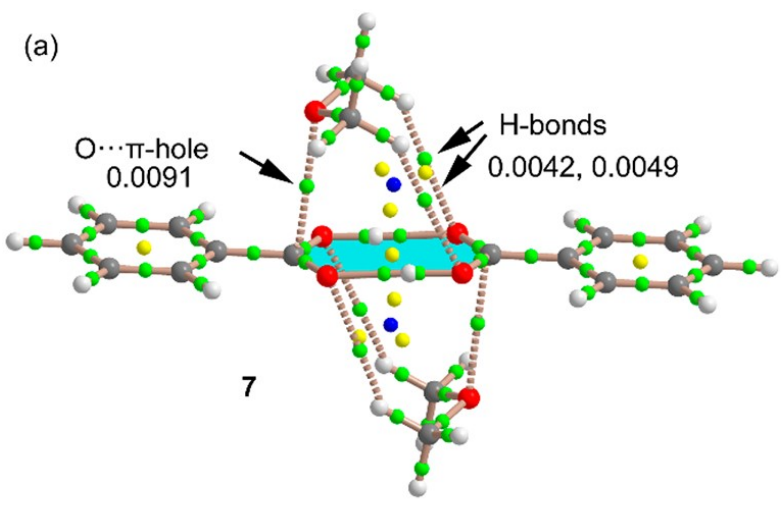

(c)

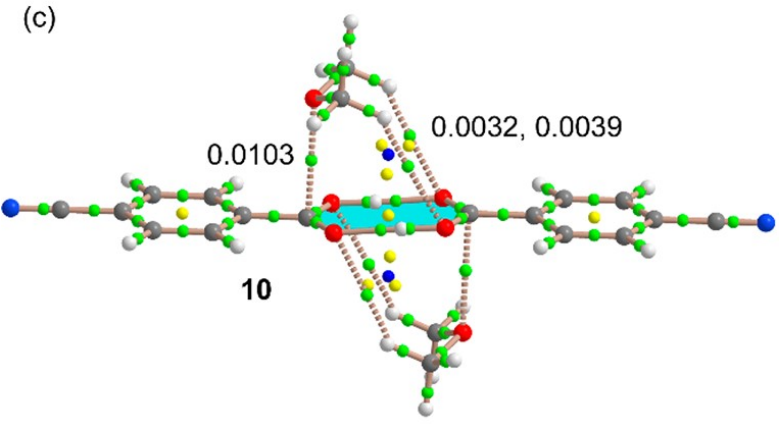

FIGURE 6

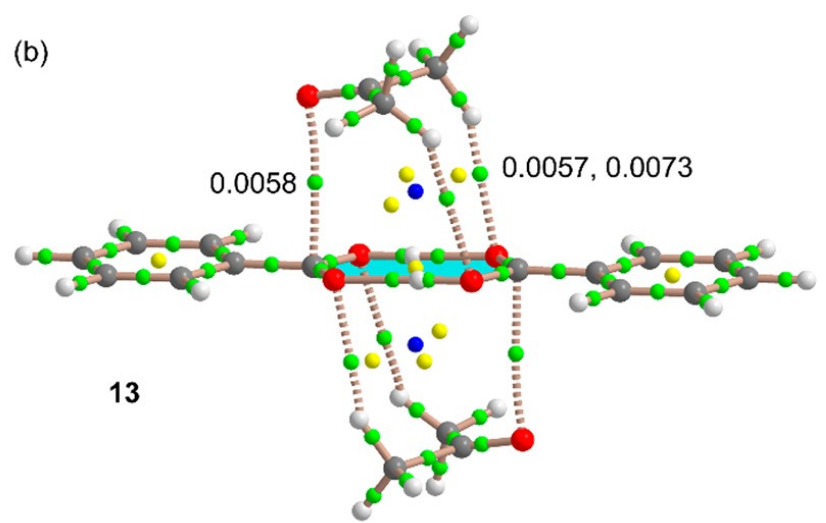

(d)

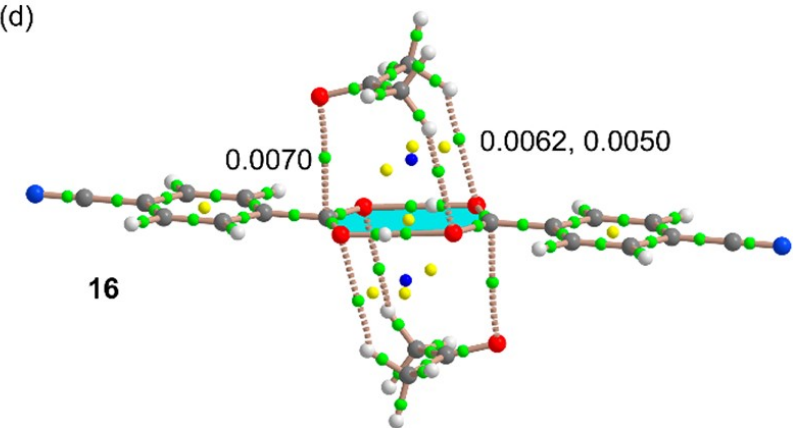

553 
FIGURE 7

555

556
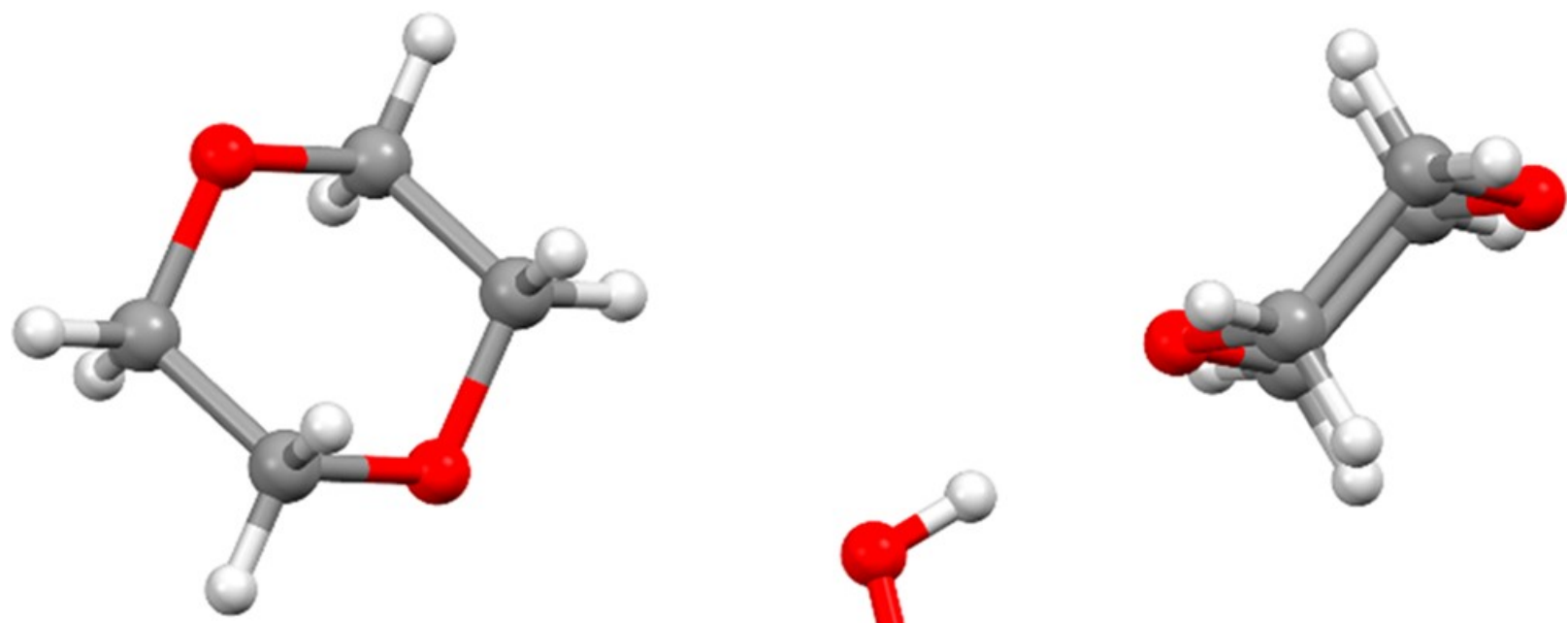

557
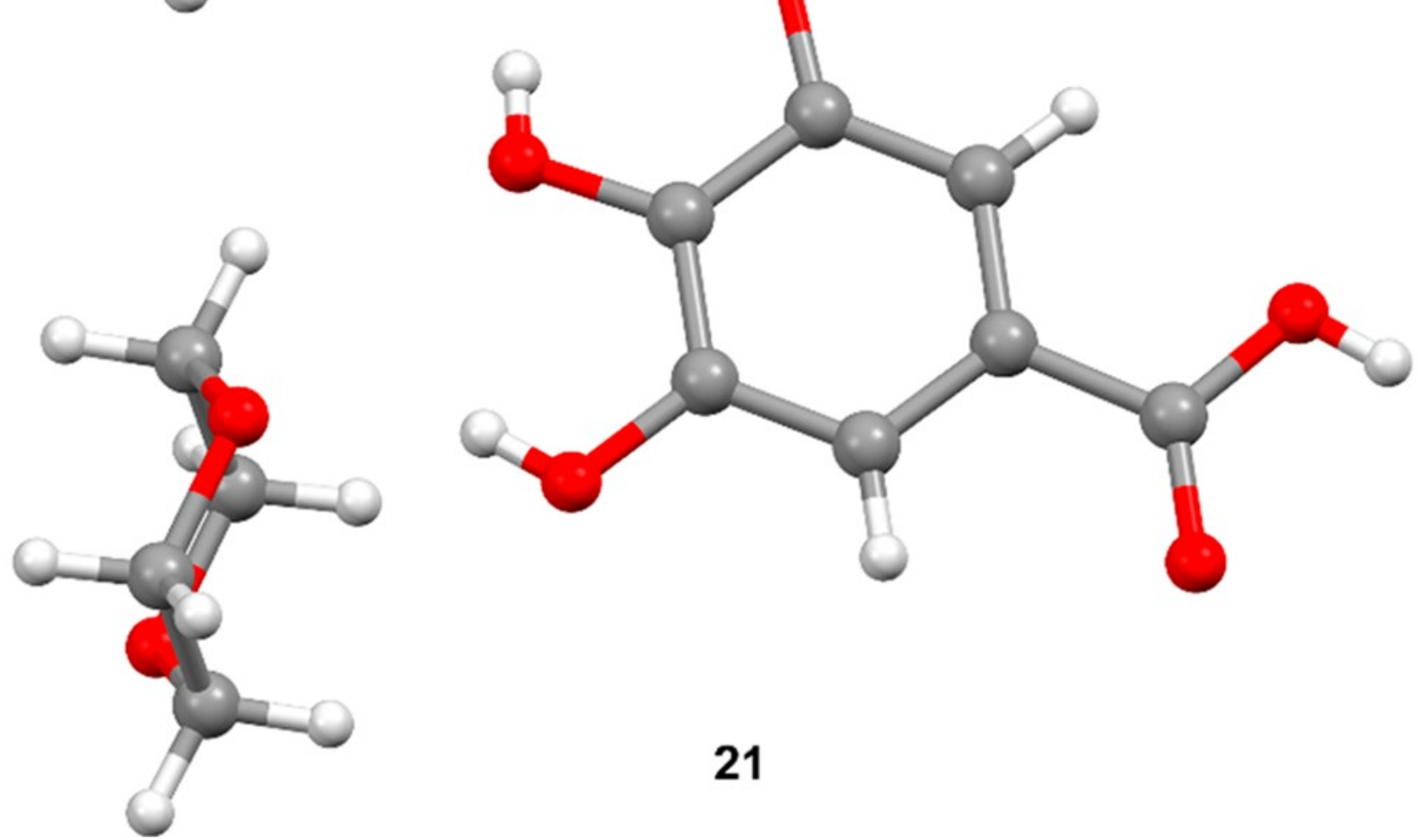

558

\section{1}




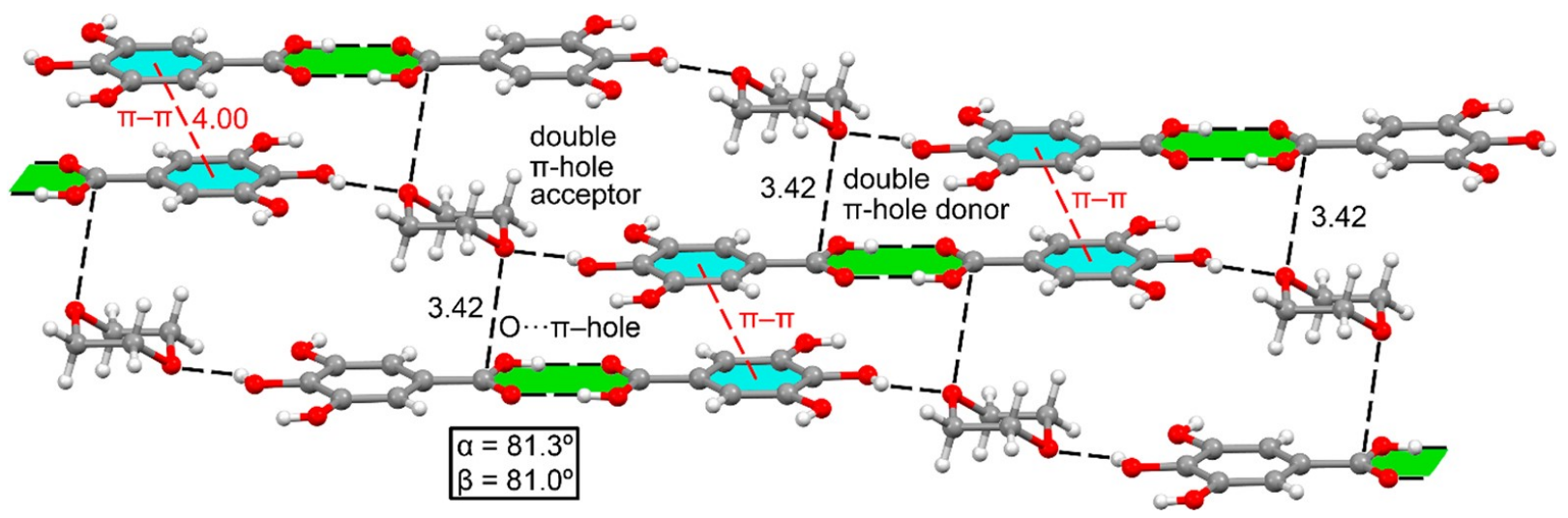


564 Table 1 Interaction Energies ( $\Delta \mathrm{E}, \mathrm{kcal} / \mathrm{mol})$, Equilibrium Distances $(\mathrm{d}, \AA)$ and $\alpha$ and $\beta$ Angles $(\mathrm{deg})$ as 565 Described in Figure 2 and the Electron Charge Density $\rho(r)$ at the Bond CP That Connects the $O$ to the 566 C Atom for Complexes 7-20 at the PBE0-D3/def2-TZVP Level of Theory

567

\begin{tabular}{|c|c|c|c|c|c|}
\hline compkx & $\Delta E$ & $d$ & $\alpha$ & $\hat{p}$ & $\rho(r)$ \\
\hline 7 & -10.2 & 291 & 81.5 & 867 & 00091 \\
\hline 8 & -9.9 & 295 & $\mathrm{saz}$ & 856 & 00084 \\
\hline 9 & -10.4 & 291 & 821 & 864 & 00091 \\
\hline 10 & -11.3 & 285 & 949 & 860 & aosoz \\
\hline 11 & -100 & 295 & 812 & 84.1 & aooss \\
\hline 12 & -9.9 & 294 & $\operatorname{saz}$ & 928 & aoose \\
\hline 13 & -107 & $30 s$ & 909 & 826 & aooss \\
\hline 14 & -10.8 & 3.13 & 927 & 87.4 & 00053 \\
\hline 15 & -11.0 & 306 & 921 & 82.8 & 00060 \\
\hline 16 & -11.5 & 298 & 901 & 812 & 00070 \\
\hline 17 & -11.1 & 3.18 & 93.5 & $\mathrm{sos}$ & aoos: \\
\hline 18 & -10.8 & 3.14 & 029 & 819 & 0.0052 \\
\hline 19 & -8.2 & 3.19 & 870 & 874 & 0.0045 \\
\hline 20 & -86 & 3.17 & s80 & 87.1 & acoso \\
\hline
\end{tabular}

